
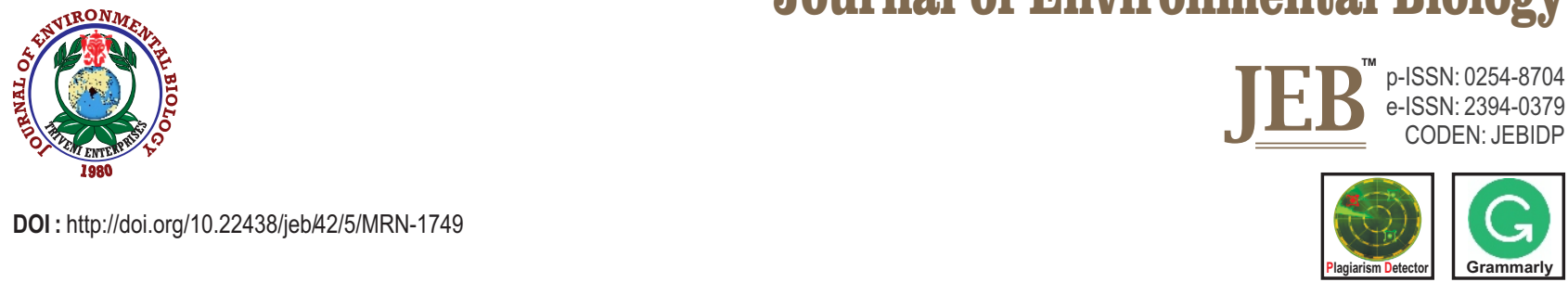

\title{
A medicinal plant Cudrania tricuspidata ameliorates allergic inflammation in mouse
}

\author{
Y.S. Kim ', A.R. Ryu', C.R.Yoon ${ }^{2}$, J.W. Choi', J.R. Huh ${ }^{3}$ and M.Y. Lee ${ }^{1,2 *}$ \\ 'Department of Medical Science, College of Medical Sciences, Soonchunhyang University, Asan, 22 Soonchunhyang-ro, 31538, Republic of Korea \\ ${ }^{2}$ Department of Medical Biotechnology, College of Medical Sciences, Soonchunhyang University, Asan, 22 Soonchunhyang-ro, 31538, Republic of \\ Korea \\ ${ }^{3}$ College of Engineering, Konkuk University, Seoul, 120 Neungdong-ro, 05029, Republic of Korea \\ *Corresponding Author Email : miyoung@sch.ac.kr
}

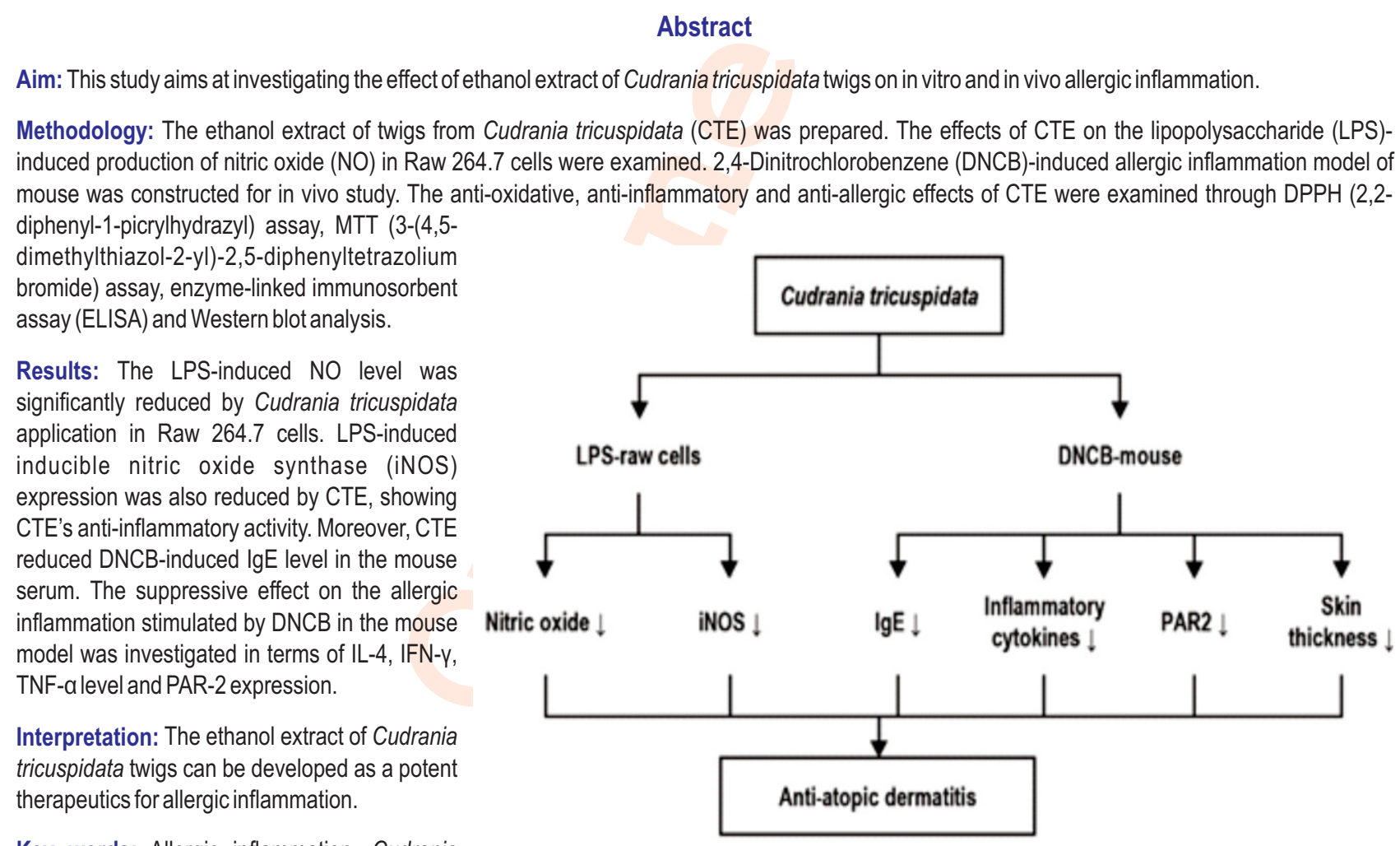

Key words: Allergic inflammation, Cudrania tricuspidata, Cytokine, IgE, PAR-2 


\section{Introduction}

Allergy is recognized as the most common chronically relapsing skin disorder accompanying allergic inflammation. Approximately, $20 \%$ of people are concerned with the fear of anaphylactic shock, or even death from allergic diseases. These include atopic dermatitis, hay fever, allergic rhinitis, food allergy, and allergic asthma (Kido-Nakahara et al., 2021). Moreover, the prevalence of allergy has been increasing for several decades. Allergy, as a complex disorder, results from multiple interactions between genetic and environmental factors, and the risk factors, cause, pathogenesis and prevalence have been demonstrated. Presently, steroids are generally accepted as the most effective drugs for allergic diseases, although they are associated with potential adverse effects including anaphylaxis (Oh et al., 2017). In the allergic reactions, mast cells act as the main site for inflammatory reaction. Activation of mast cells with immunoglobulin $\mathrm{E}$ ( $\mathrm{lgE}$ )-dependent and independent stimulation takes place due to fusion of cytoplasmic granules and plasma membrane and then the vasoactive mediators are quickly released by degranulation of mast cells. Especially, histamine among various mediators is the key vasoactive mediator in the immediate hypersensitivity (Thangam et al., 2018).

Among allergic diseases, atopic dermatitis is a common inflammatory skin disease characterized by Th1/Th2 cytokine imbalance, elevated $\mathrm{lgE}$, and mast cell infiltration. Atopic dermatitis shows dry skin, pruritus, eczema and keratinization (Savinko et al., 2012; Newell et al., 2013). It occurs due to the production of interleukin-4 (IL-4) produced from Th2 cells and interferon-gamma (IFN- $\gamma$ ) from Th1 cells (Bonness and Bieber, 2007; Dang et al., 2015). Within the Th1/Th2 paradigm, it is characterized as a Th2 type disorder and shows Th2-like immune responses at an early acute phase, however, switched over to more Th1-like profile on emergence of chronic phase (Abramovits, 2005; Jung et al., 2017). The level of IFN-y in the patients increases during the progression of atopic dermatitis from acute to chronic phase (Su et al., 2017). In particular, there still exist some variations due to heterogeneous propeties which needs to be considered, such as Th1-activated intrinsic AD, Th1infiltrating chronic $A D$, and Th17 involvement(Tokura et al., 2018).

Medicinal plants have been used for treating various skin diseases on numerous occasions (Tresch et al., 2019; Kumar et al., 2013). Medicinal plants, externally used for the treatment of atopic dermatitis include matricaria flower (Matricariarecutita L.), marigold (Calendula officinalis L.), aloe vera (Aloe barbadensis), and St. John's wort (Hypericum perforatum L.). These plants have anti-inflammatory activity affecting various stages of inflammation, inhibiting formation of cytokines and eicosanoids, and preventing inflammatory reaction cascade.

One of the advantages of medicinal plants is low toxicity and side effects with higher medicinal ability (Kumar et al., 2013). Cudrania tricuspidata, a perennial plant of family Moraceae, has various medicinal and nutritional values (Kim et al., 2016). It has been traditionally used for treating several diseases including cancers, diabetes, tuberculosis and contusions in EastAsia (Choi et al., 2015). However, the information on the treatment of allergic inflammation by $C$. tricuspidata is limited. In this investigation, the suppressive effect of ethanol extract of twigs from C. tricuspidata (CTE) on the allergic inflammation was examined in LPS-stimulated Raw 264.7 cells and 2.4dinitrochlorobenzene (DNCB)-induced allergic inflammatory mouse model.

\section{Materials and Methods}

Preparation of ethanol extract of Cudrania tricuspidata: C. tricuspidata twigs were purchased from Sinan C. tricuspidata Farming Corporation (Sinan-gun, Korea). Dried twigs of $C$. tricuspidata were extracted with ethanol for $72 \mathrm{hr}$, and then the extract was filtered with Whatman No.2 filter paper. After filtration, the resultant ethanol extract was evaporated, freeze-dried, and stored at $-60^{\circ} \mathrm{C}$. The crude extract was resuspended in ethanol and filtered using a $0.4 \mu \mathrm{m}$ membrane for the experiments (Song etal., 2017).

Antioxidant assay: DPPH radical cation scavenging activity of CTE was estimated following the method of Blois (1958) with some modification. A $0.2 \mathrm{mM} \mathrm{2,2-diphenyl-1-} \mathrm{picrylhydrazyl}$ (DPPH) radical (Sigma-Aldrich, MO, USA; $50 \mu \mathrm{l}$ ) was added into each extract, and absorbance was then read at $520 \mathrm{~nm}$ on a spectrophotometer (Sunrise, Tecan, Männedorf, Switzerland). $A B T S$ radicals scavenging activity was assayed by the method of Leelarungrayub et al. (2006) with some modification. ABTS solution was added rapidly to the extract and the decrease in the absorbance was read at $620 \mathrm{~nm}$.

Estimation of total phenolic content: Total phenolic content in CTE was estimated by the modified method of Folin-Ciocalteu (1927). An aqueous solution containing $1 \mathrm{ml}$ of $C$. tricuspidata extract or standard was mixed with $1 \mathrm{ml}$ of $2 \%$ sodium carbonate solution and $1 \mathrm{ml}$ of $10 \%$ Folin-Ciocalteu phenol reagent. The mixture was incubated at room temperature for $10 \mathrm{~min}$ and then the absorbance of mixture was detected at $750 \mathrm{~nm}$. The average absorbance values obtained at different concentrations of gallic acid were used to plot the calibration curve, and the measurement for sample was compared to a calibration curve of gallic acid. The results were expressed in milligrams of gallic acid equivalents per gram of the sample.

Estimation of total flavonoid content: Flavonoid content was determined by aluminum chloride colorimetric method. The quercetin standard diluted from $200 \mu \mathrm{g} \mathrm{ml}^{-1}$ to $5 \mathrm{\mu g} \mathrm{ml}^{-1}$ was used for the calibration curve. A $0.6 \mathrm{ml}$ of diluted standard quercetin solutions and C. tricuspidata extract was mixed with $0.6 \mathrm{ml}$ of $2 \%$ aluminum chloride. The total $1.2 \mathrm{ml}$ solution was incubated at room temperature for $1 \mathrm{hr}$. The absorbance was read against blank at $420 \mathrm{~nm}$ on ELISA plate reader (TECAN, sunrise). The concentration of total flavonoid in the mixture was calculated from the calibration ratio and expressed in $\mathrm{mg}$ quercetin equivalent $\mathrm{g}^{-1}$ 
for dried extract volume.

MTT assay for cell viability: The 3-(4,5-dimethylthiazol-2-yl)2,5-diphenyl tetrazolium bromide (MTT) assay is one of the most widely used cytotoxicity screen method due to its simple and rapid procedure (Mosmann, 1983). The maximum concentration of CTE at which the cell viability was not affected was determined by MTT assay. In brief, the cells were cultured in 96-well plate at a density of $1 \times 10^{6}$ cells $\mathrm{ml}^{-1}$. The cells were then treated with varying concentrations of CTE. After $24 \mathrm{hr}$, the cells were washed and treated with MTT and then incubated in dark for $2 \mathrm{hr}$ at $37^{\circ} \mathrm{C}$. After the formazan formation, $100 \mu \mathrm{LMSO}$ per well was added, and the absorbance was read at $570 \mathrm{~nm}$ using a microplate ELISA reader (Sunrise, Tecan, Switzerland) (Hur etal., 2020).

Estimation of nitrite production: Nitrite concentration in the conditioned medium was measured as Griess reaction which is known as an indicator of NO production. Each supernatant was mixed with the same volume of Griess reagent $(1 \%$ sulfanilamide in $5 \%$ phosphoric acid and $0.1 \%$ naphthyl ethylenediamine dihydrochloride in distilled water). The absorbance of the mixture was read at $570 \mathrm{~nm}$ on ELISA reader (Sunrise, Tecan, Switzerland) (Saville, 1958; Jin and Lee, 2018).

Animals: Eight-week-old male Balb/c mice were purchased from ORIENT Inc. (Sungnam, Korea). Mice were kept in each cage and maintained at $25^{\circ} \mathrm{C}$ under $12 \mathrm{hr}$ light/dark cycle throughout the study. The animal study was approved by the Institutional Animal Care and Use Committee (2020-0039).

Allergic inflammation-induced mouse model: DNCB-induced allergic inflammation was produced with 2,4dinitrochlorobenzene (Ryu and Lee, 2019). Dorsal hair of each group of 5 mice was shaved with hair removal cream. Mice were assigned to one of four groups (five mice each): normal (nontreated group); DNCB (negative control group); dexamethasone (positive control group, $2.5 \mathrm{mg} \mathrm{kg}^{-1}$ dexamethasone in distilled water); CTE treating group (mice sensitized with DNCB and treated with $200 \mu \mathrm{l}$ of $75 \mathrm{mg} \mathrm{ml}^{-1}$ CTE in distilled water). Induction of allergic inflammation was achieved by topical application of $200 \mu \mathrm{l}$ of $1 \%$ DNCB in 4:1 (v/v) acetone/olive oil for 9 times for 3 weeks. After 5 days, $0.4 \%$ DNCB was daily applied to the back and ear for fifteen days. After 40 days of first application, all groups of mice were sacrificed, and blood, ear and dorsal skins were collected.

IgE and cytokine determination via ELISA: Mouse sera were prepared by centrifuging isolated blood at $20,000 \times \mathrm{g}$ for $30 \mathrm{~min}$ at $4^{\circ} \mathrm{C}$ and collecting the supernatants. Serum IgE, IL-4, IFN- $\gamma$, and TNF-a concentrations were quantified with ELISA kit (BD, CA, USA) as per manufacturer's protocol. Cytokine levels were normalized using a protein assay kit (BD, CA, USA) and calculated as picogram per milligram $\left(\mathrm{pg} \mathrm{mg}^{-1}\right)$ of total protein. Color development was measured at $450 \mathrm{~nm}$ on ELISA reader (TECAN, Männedorf, Switzerland).
Western blot: The whole tissue lysate was prepared in RIPA buffer and $25 \mu \mathrm{g}$ of proteins were separated by SDS-PAGE gels. The gels were transferred onto activated polyvinylidene difluoride (PVDF) membranes for $1 \mathrm{hr}$ at $400 \mathrm{~mA}$. The PVDF membranes were blocked for $2 \mathrm{hr}$ in blocking solution (5\% bovine serum albumin or $5 \%$ skim milk) at room temperature. The membrane was then incubated for $18 \mathrm{hr}$ at $4^{\circ} \mathrm{C}$ with individual primary antibodies. Secondary antibodies were visualized on Supernova ECL Western blotting detection system (Cyanagens.r.l., Italy) and the images were taken with scanner system of Seni-Q 2000 (Lugen Sci Co. Ltd., Korea). The visualized areas were measured using Image J software to quantify band intensities.

Statistical analyses: Significance was determined by One-way analysis of variance followed by Tukey's HSD test. The data were statistically significant at $P<0.05$.

\section{Results and Discussion}

The antioxidative activity of ethanol extracts of $C$. tricuspidata twigs was measured by DPPH and ABTS free radical scavenging assay (Data not shown). The $\mathrm{IC}_{50}$ value of $C$. tricuspidata extract was determined to be $94.1 \mathrm{\mu g} \mathrm{ml}^{-1}$ and $58.46 \mu \mathrm{g} \mathrm{ml}^{-1}$ for DPPH and ABTS free radical scavenging activity, respectively, indicating significant antioxidative activity of C. tricuspidata extract. Further, the total phenolic and flavonoid contents of $C$. tricuspidata extract were also determined (Data not shown). C. tricuspidata extract showed high total phenolic content of $209.83 \mathrm{mg} \mathrm{g}^{-1}$ equivalent garlic acid. The total flavonoid content of $C$. tricuspidata extract was $41.95 \mathrm{mg} \mathrm{g}^{-1}$ equivalent quercetin. Polyphenols, such as flavonoids, gallic acid, quercetin, and salicin, are reported to possess anti-inflammatory, antibacterial, and antioxidant activities in many studies (Saracila et al., 2021). In particular, the antioxidant activity of polyphenols acts in two kinds of ways which are directly scavenging ROS as a donor of electron or hydrogen atom or inducing antioxidant enzymes (SOD, CAT, GST, HO1, etc.) (Sandoval-Acuna et al., 2014; Saracila et al., 2021).

To examine in vitro anti-inflammatory effects of $C$. tricuspidata extract, the level of NO production and iNOS expression was measured in the LPS-induced Raw 264.7 cells. As shown in Fig. 1A, LPS-induced NO level was highly reduced by $C$. tricuspidata extract application. Also, the expression of LPS-induced iNOS expression was diminished by $C$. tricuspidata extract application as indicated on the Western blot gel. These data suggest the in vitro anti-inflammatory activity of C. tricuspidata extract, via regulating NO production and iNOS expression (Camuesco et al., 2004). The suppressive effect of C. tricuspidata extract on the allergic inflammation in 2,4dinitrochlorobenzene (DNCB)-induced mouse model was investigated, as depicted in Fig. 2. The repeated application of DNCB on the shaved dorsal skin of mice induced atopic dermatitis-like skin inflammation such as erythema, lichenification, scaliness, dryness, and thickening as shown in 
(A)

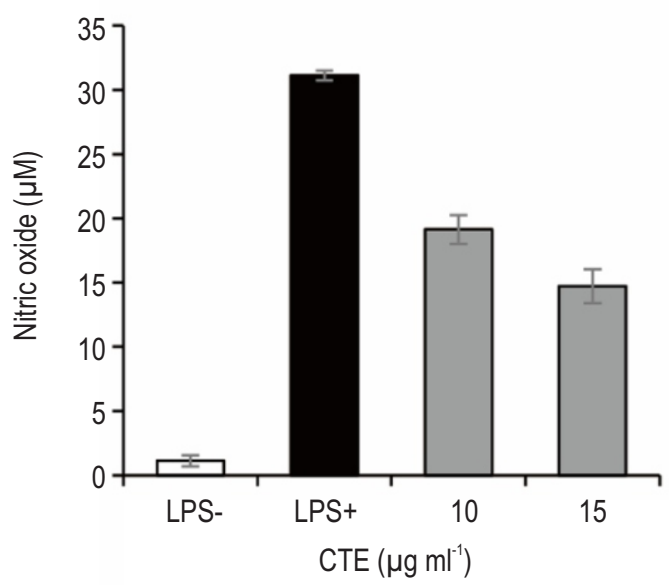

(B)

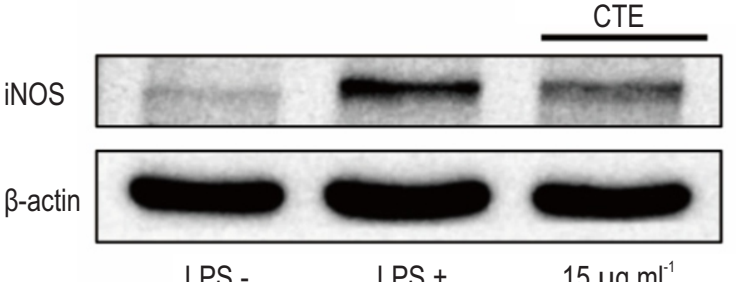

LPS -

LPS +

$15 \mu \mathrm{g} \mathrm{ml}$

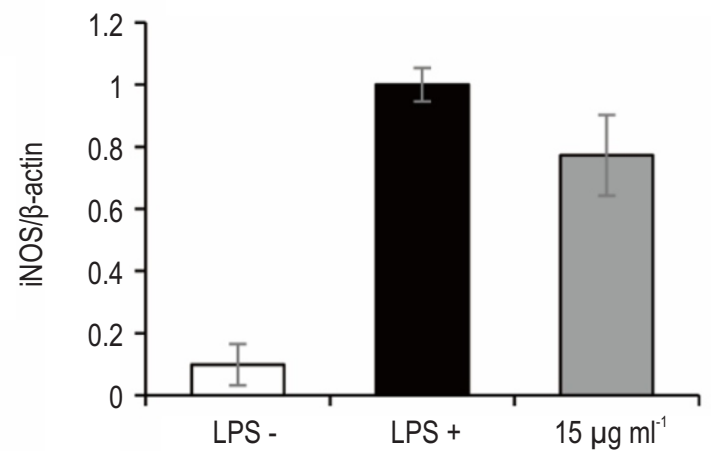

Fig. 1: (A) Effect of Cudrania tricuspidata extract on LPS-induced nitric oxide and (B) iNOS protein expression in Raw 264.7 cells.

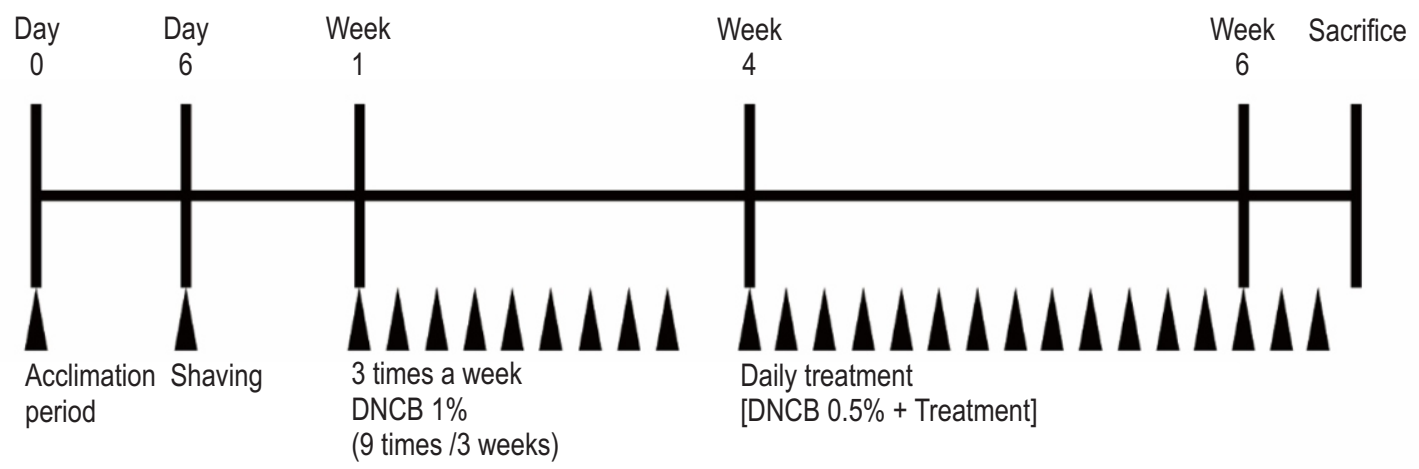

Fig. 2: Schematic diagram of the protocol to induce atopic dermatitis -like lesions in mouse.

the DNCB group (Fig. 3A). However, C. tricuspidata extract treatment reduced the severity of $A D$-like symptoms, showing similar effect with dexamethasone treatment group.

Symptoms of atopic dermatitis include thickening of the epidermis and dermis, infiltration of mast cells and eosinophils, overexpression of Th2 cytokines, and increased lgE production (Hong et al., 2020). Among them, skin thickening is a well-known symptom of atopic dermatitis, and continuous inflammation and allergic reactions can cause thickening and hardening of skin. As shown in Fig. 3B, C. tricuspidata extract reduced the epidermis thickness effectively and significantly.

The average ear thickness of DNCB group was $0.52 \mathrm{~mm}$, which was 2.4 times higher than the average ear thickness of the normal group. However, the average ear thickness of the $C$. tricuspidata extract-treated group was $0.4 \mathrm{~mm}$, showing statistically similar data with dexamethasone group $(p<0.05)$. Atopic dermatitis has been known to be driven by strong type 2 immune responses, however, additional activation of Th22, Th17/IL-23, and Th1 cytokine pathways contribute to pathogenesis of atopic dermatitis, depending on the subtype of disease (Brunner et al., 2017). In addition, atopic dermatitis is currently considered as a primarily T cell-driven disease, as demonstrated by the clinical use of cyclosporine, efalizumab, and alefacept which are categorized as a broad T cell-targeting therapeutics. In addition, atopic dermatitis can be classified into two types: extrinsic and intrinsic (Suárez-Fariñas et al., 2013). Extrinsic atopic dermatitis is characterized by high lgE level and skin barrier impairment (Choi et al., 2003). However, normal lgE 
(A)

\section{DNCB}

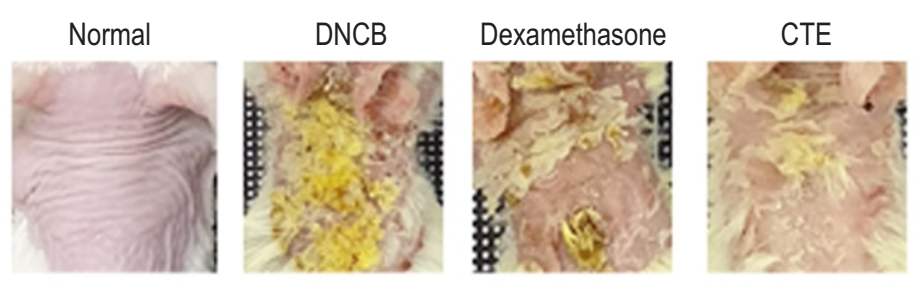

(B)

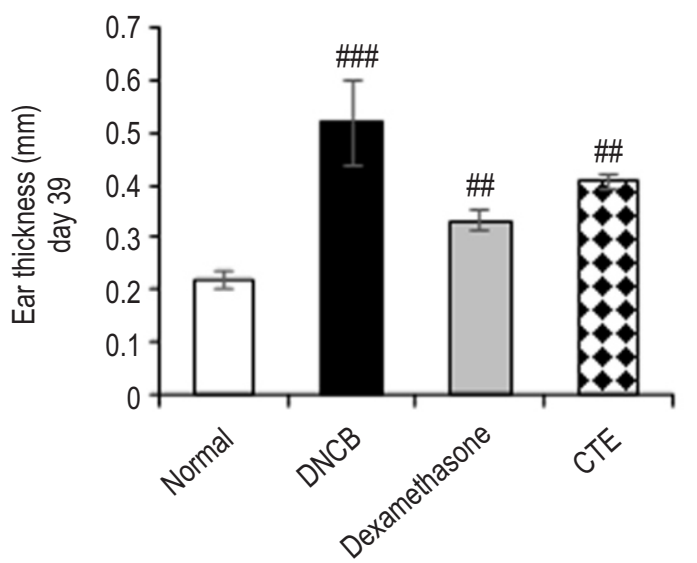

Fig. 3: (A) Representative photographs of mouse dorsal skin at 39 days after $A D$ induction by application of 2,4-dinitrochlorobenzene and (B) ear thickness. Data are presented as means $\pm S D$ and analyzed with ANOVA. ${ }^{m} P<0.05$, versus the normal group. ${ }^{. \prime} P<0.05$, versus the DNCB group.
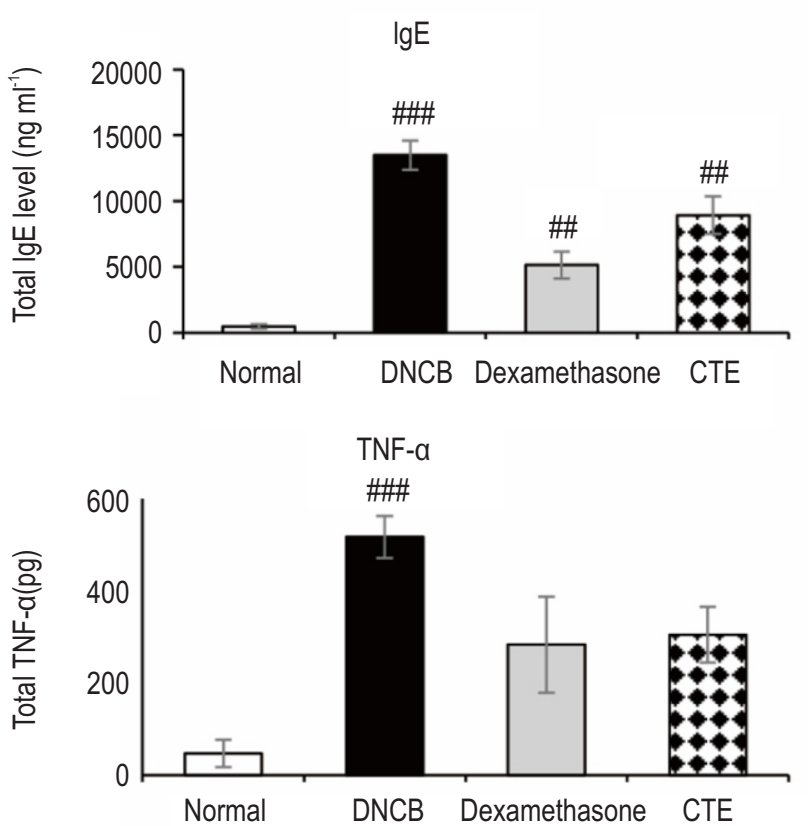

IL-4
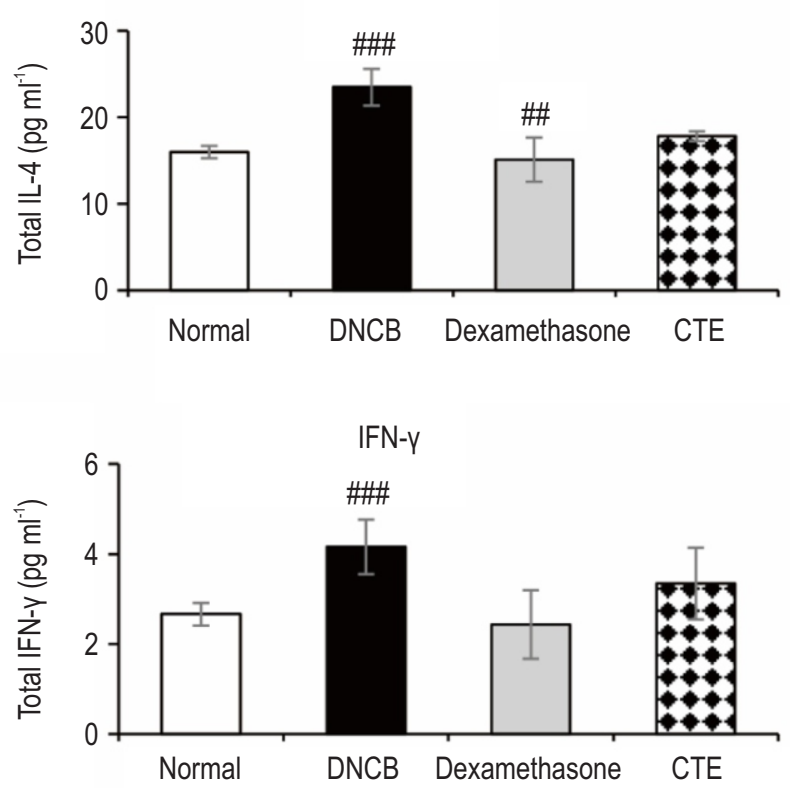

Fig. 4: Serum levels of IgE, IL-4, IFN-y and TNF-a in the allergic inflammation-induced Balb/c mice. Data are presented as means \pm SD and analyzed with ANOVA. ${ }^{\prime \prime} P<0.05$, versus the normal group. ${ }^{. \prime} P<0.05$, versus the DNCB group.

level and higher level of IFN- $\gamma$ and low levels of IL-4 and IL-13 are found in intrinsic type. Extrinsic atopic dermatitis prevalence is $70-80 \%$ with allergen specific IgE against aeroallergens and foods. However, the intrinsic atopic dermatitis makes up the remaining $20-30 \%$ with woman predominance and does not have allergen specific $\lg E$ (Tokura, 2010). The serum IgE, the prime inflammatory mediator in atopic dermatitis, was measured to assess anti-allergic effect of $C$. tricuspidata extract in Fig. 4 . In the DNCB-induced allergic inflammatory group, the IgE level was approximately 29 times higher than the normal group. However, upon treating $C$. tricuspidata extract, the lgE level was reduced by about $33.8 \%$. This result suggests that $C$. tricuspidata extract can effectively suppress serum IgE induced by DNCB. Enhanced serum IgE production might be due to Th2 cell activation, which, in 

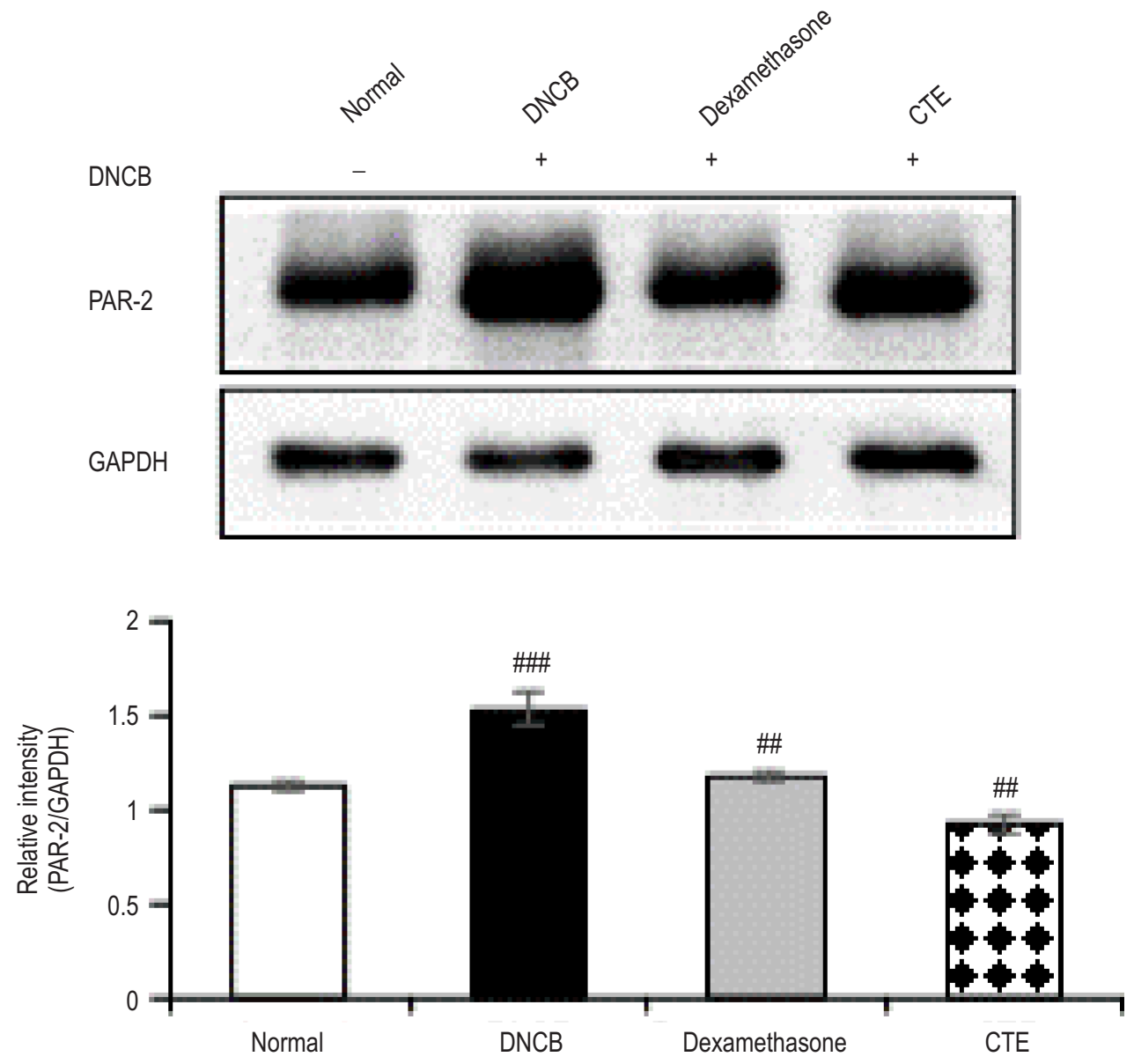

Fig. 5: Western blot analysis of PAR-2 protein expression in dorsal lesion of allergic inflammation-induced Balb/c mice.

turn, results in the secretion of IL-4, IL-5, IL-9, and IL-13. Among them, IL-4 mostly regulates lgE production (Chiricozzi et al., 2020). It is known that Th2 cells participate in acute phase of AD, while Th1 cells are involved in chronic atopic dermatitis. Among the Th2 cytokines, IL-4 plays an important role in allergic inflammation via enhancement of IgE production (Sy et al., 2006), while Th1 cytokine, IFN- $\gamma$, plays a pivotal role for dermatitis occurrence. The levels of IL-4 and IFN- $y$ in mouse serum were assessed by ELISA in Fig. 4. The levels of IL-4 and IFN- $\gamma$ were significantly increased by DNCB application, however, CTE treatment significantly reduced the level of IL-4 and IFN-y (Fig. 4). DNCB-induced TNF-a was also reduced by CTE treatment. Protease-activated receptor-2 (PAR-2) has been involved in inflammation, obesity and metabolism. Interestingly, the inflammatory roles of PAR-2 have been demonstrated in the atopic dermatitis mouse model, and PAR-2 agonists increased itching by causing responsiveness of sensory nerves to reaction with antihistamines (Heuberger and Schuepbach, 2019).

In addition, PAR-2 is involved in the generation of $A D$ aggravating factor TSLP (thymic stromal lymphopoietin) by epidermal keratinocytes (Tokura et al., 2018). Current knowledge of PAR-2 has shown a more complicated activities involved in the regulation of epidermal barrier, keratinocyte differentiation, cutaneous tumorigenesis and pigmentation (Henehan and De Benedetto, 2019). The atopic dermatitis symptoms are known to be exacerbated by the increase of PAR-2 expression, which ultimately activates IKB kinase and nuclear factor kappa B (NFkB) (Barr et al., 2019). As shown in Fig. 5, DNCB-induced PAR-2 expression was reduced by CTE treatment. Thus, CTE treatment might modulate PAR-2 associated inflammatory signals linked with NFkB (Tanaka et al., 2011). In this investigation, the in vitro antiallergic inflammatory effects of $C$. tricuspidata extract were demonstrated via regulating NO and iNOS production in LPSinduced Raw 264.7 cells. Moreover, CTE also reduced DNCBinduced $\lg E$ and IL-4, TNF- $\alpha$ and IFN- $\gamma$. PAR-2 expression also decreased in mouse AD-like model. Further studies are needed to elucidate the mechanism by which C. tricuspidata extract reducs the prevalence and progression of atopic dermatitis. Taken together, CTE can be used for the development of natural therapeutics for atopic dermatitis. 


\section{Acknowledgments}

This research was supported by $\mathrm{X}$ mindCorps program of National Research Foundation of Korea (NRF) funded by the Ministry of Science, ICT (2019H1D8A110562211). This research was also supported by Soonchunhyang University.

\section{Add-on Information}

Authors' contribution: Y.S. Kim: Investigation, data analysis, writing of original draft; A.R. Ryu: Investigation, data analysis; C.R. Yoon: Data analysis; J.W. Choi: Data analysis; J.R. Huh: Data validation; M.Y. Lee: Conceptualization, principal investigation, revision of manuscript.

Research Content: The research content of manuscript is original and has not been published elsewhere.

Ethical approval : The animal study was approved by the Institutional Animal Care and Use Committee (2020-0039).

Conflict of interest :The author declares that there is no conflict of interest

\section{Data from other sources: Not applicable}

Consent to publish : All the authors agree to publish the paper in Journal of Environmental Biology.

\section{References}

Abramovits, W.: Atopic dermatitis. J. Am. Acad. Dermatol., 53, S86-S93 (2005)

Barr, T.P., C. Garzia, S. Guha, E.K. Fletcher, N. Nguyen, A.J. Wieschhaus, L. Ferrer, L. Covic and A. Kuliopulos: PAR2 pepducin-based suppression of inflammation and itch in atopic dermatitis models. J. Invest. Dermatol., 139, 412-421 (2019).

Blois, M.S.: Antioxidant determinations by the use of a stable free radical. Nature, 181, 1199-1200 (1958).

Bonness, S. and T. Bieber: Molecular basis of atopic dermatitis. Curr. Opin. Allergy Clin. Immunol., 7, 382-386 (2007).

Brunner, P.M., E. Guttman-Yassky and D.Y. Leung: The immunology of atopic dermatitis and its reversibility with broad-spectrum and targeted therapies. J. Allergy Clin. Immunol., 139, S65-S76 (2017)

Camuesco, D., M. Comalada, M.E. Rodríguez-Cabezas, A. Nieto, M.D. Lorente, A. Concha, A. Zarzuelo and J. Gálvez: The intestinal anti-inflammatory effect of quercitrin is associated with an inhibition in iNOS expression. Br. J. Parmacol., 143, 908-918 (2004).

Chiricozzi, A., M. Maurelli, K. Peris and G. Girolomoni: Targeting IL-4 for the treatment of atopic dermatitis. Immunot. Ther., 9, 151-156 (2020).

Choi, D.J., Y.J. Lee, Y.K. Kim, M.H. Kim, S.R. Choi, S.S. Kim and A.R. Youn: Physicochemical properties and antioxidant activities of different parts of Kkujippong (Cudrania tricuspidata Bureau) from Miryang. Korean J. Food Cook. Sci., 31, 510-514 (2015).

Choi, S. J., M.G. Song, W.T. Sung, D.Y. Lee, J.H. Lee, E.S. Lee and J.M. Yang: Comparison of transepidermal water loss, capacitance and $\mathrm{pH}$ values in the skin between intrinsic and extrinsic atopic dermatitis patients. J. Korean Med. Sci., 18, 93-96 (2003).
Dang, L., L. He, Y. Wang, J. Xiong, B. Bai and Y. Li: Role of the complement anaphylatoxin C5a-receptor pathway in atopic dermatitis in mice. Mol. Med. Rep., 11, 4183-4189 (2015).

Folin $\mathrm{O}$. and V. Ciocalteu: On tyrosine and tryptophane determinations in proteins. J. Biol. Chem., 73, 627-650 (1927).

Henehan, M. and A. De Benedetto: Update on protease-activated receptor 2 in cutaneous barrier, differentiation, tumorigenesis and pigmentation, and its role in related dermatologic diseases. Exp. Dermatol., 28, 877-885 (2019).

Heuberger, D.M. and R.A. Schuepbach: Protease-activated receptors (PARs): Mechanisms of action and potential therapeutic modulators in PAR-driven inflammatory diseases. J. Thromb., 17 1-24 (2019).

Hong, S., B. Lee, J.H. Kim, E.Y. Kim, M. Kim, B. Kwon, H.R. Cho, Y. Sohn and H.S. Jung: Solanum nigrum Linne improves DNCB-induced atopic dermatitis-like skin disease in BALB/c mice. Mol. Med. Rep., 22, 2878-2886 (2020).

Hur, G. H., S.C. Han, A.R. Ryu, Y. Eom, J.W. Kim and M.Y. Lee: Effect of oligoarginine conjugation on the antiwrinkle activity and transdermal delivery of GHK peptide. J. Pept. Sci., 26, e3234 (2020).

Jin, S. and M.Y. Lee: The ameliorative effect of hemp seed hexane extracts on the Propionibacterium acnes-induced inflammation and lipogenesis in sebocytes. PLoS ONE, 13, e0202933 (2018).

Jung, K.H., H. Baek, M. Kang, N. Kim, S.Y. Lee and H. Bae: Bee venom phospholipase A2 ameliorates house dust mite extract induced atopic dermatitis like skin lesions in mice. Toxins, 9, 68 (2017).

Kido-Nakahara, M., B. Wang, F. Ohno, G. Tsuji, D. Ulzii, M. Takemura, M. Furue and T. Nakahara: Inhibition of mite-induced dermatitis, pruritus, and nerve sprouting in mice by the endothelin receptor antagonist bosentan. Allergy, 76, 291-301 (2021).

Kim, D.C., C.S. Yoon, T.H. Quang, W. Ko, J.S. Kim, H. Oh and Y.C. Kim: Prenylated flavonoids from Cudrania tricuspidata suppress lipopolysaccharide-induced neuroinflammatory activities in BV2 microglial cells. Int. J. Mol. Sci., 17, 255 (2016).

Kumar, S., B.S. Bajwa, S. Kuldeep and A.N. Kalia: Anti-inflammatory activity of herbal plants: Areview. IJAPBC, 2, 272-281 (2013).

Leelarungrayub, N., V. Rattanapanone, N. Chanarat and J.M. Gebicki: Quantitative evaluation of the antioxidant properties of garlic and shallot preparations. Nutrition, 22, 266-274 (2006)

Mosmann, T.: Rapid colorimetric assay for cellular growth and survival: Application to proliferation and cytotoxicity assays. J. Immunol. Methods, 65, 55-63 (1983).

Newell, L., M.E. Polak, J. Perera, C. Owen, P. Boyd, C. Pickard and M.R. Ardern-Jones: Sensitization via healthy skin programs Th2 responses in individuals with atopic dermatitis. J. Invest Dermatol., 133, 2372-2380 (2013).

Oh, I.H., Y.H. Rha, T. Fujisawa and K.S. Lee: Risk factors of allergic disease: A study with a large data set. Biomed. Res. Int., 2017, 8969352 (2017).

Ryu, A.R. and M.Y. Lee: Ameliorative effect of chlorin e6-mediated photodynamic therapy on DNCB-induced atopic dermatitis-like skin lesions in mice. Mol. Cell. Toxicol., 15, 265-270 (2019).

Sandoval-Acuna, C., J. Ferreira and H. Speisky: Polyphenols and mitochondria: an update on their increasingly emerging ROSscavenging independent actions. Arch. Biochem. Biophys., 559, 75-90 (2014)

Saracila M., T.D. Panaite, C.P. Papuc and R.D. Criste: Heat stress in broiler chickens and the effect of dietary polyphenols, with special reference to willow (Salix spp.) bark supplements-a review. Antioxidants (Basel), 10, 686 (2021).

Saville B.: A scheme for the colorimetric determination of microgram amount of thiols. Analyst, 83, 670-672 (1958).

Savinko, T., S. Matikainen, U. Saarialho-Kere, M. Lehto, G. Wang, S. 
Lehtimäki and H. Alenius: IL-33 and ST2 in atopic dermatitis: Expression profiles and modulation by triggering factors. $J$. Investig. Dermatol., 132, 1392-1400 (2012).

Song, S.H., S.H. Ki, D.H. Park, H.S. Moon, C.D. Lee, I.S. Yoon and S.S. Cho: Quantitative analysis, extraction optimization, and biological evaluation of Cudrania tricuspidata leaf and fruit extracts. Molecules, 22, 1489 (2017).

Su, C., T. Yang, Z. Wu, J. Zhong, Y. Huang, T. Huang and E. Zheng: Differentiation of T-helper cells in distinct phases of atopic dermatitis involves Th1/Th2 and Th17/Treg. Eur. J. Inflamm., 15, 46-52 (2017)

Suárez-Fariñas, M., N. Dhingra, J. Gittler, A. Shemer, I. Cardinale, C. de Guzman Strong, J.G. Krueger and E. Guttman-Yassky: Intrinsic atopic dermatitis shows similar $\mathrm{TH} 2$ and higher TH17 immune activation compared with extrinsic atopic dermatitis. J. Allergy Clin. Immunol., 132, 361-370 (2013).

Sy, L.B., Y.L. Wu, B.L. Chiang, Y.H. Wang and W.M. Wu: Propolis extracts exhibit an immunoregulatory activity in an OVA-sensitized airway inflammatory animal model. Int. Immunopharmacol., 6, 1053-1060 (2006).

Tanaka, R.J., M. Ono and H.A. Harrington: Skin barrier homeostasis in atopic dermatitis: feedback regulation of kallikrein activity. PLOS ONE, 6, e19895(2011).

Thangam, E.B., E.A. Jemima, H. Singh, M.S. Baig, M. Khan, C.B. Mathias, M.K. Church and R. Saluja: The role of histamine and histamine receptors in mast cell-mediated allergy and inflammation: The hunt for new therapeutic targets. Front. Immunol., 9, 1873 (2018).

Tokura, Y., P. Phadungsaksawasdi and T. Ito: Atopic dermatitis as Th2 disease revisited. J. Cutaneous Immunol. Aller., 1, 158-164 (2018).

Tokura, Y.: Extrinsic and intrinsic types of atopic dermatitis. J. Dermatol. Sci., 58, 1-7 (2010).

Tresch, M., M. Mevissen, H. Ayrle, M. Melzig, P. Roosje and M. Walkenhorst: Medicinal plants as therapeutic options for topical treatment in canine dermatology? A systematic review. BMC Vet. Res., 15, 1-19 (2019). 